\title{
Schiff Base Transition Metal Complexes for ROP of $L$-Lactide
}

\author{
S. Mantri, H. C. Pradhan, T. Maharana, and A. K. Sutar
}

\begin{abstract}
A Series of Schiff base transition metal complexes have been synthesized and its reactivity for the ring-opening polymerization (ROP) of lactide has been studied. These metal complexes were synthesized by the reactions of metal salt solution with one molar equivalent of bulky Schiff-base ligand in methanol under nitrogen atmosphere. These complexes have been tested as initiators for the ring-opening polymerization of lactide with variation of concentration, time, solvent, etc. The transition metal complexes allow controlled ring-opening polymerization as shown by the linear relationship between the percentage conversion and the number-average molecular weight.
\end{abstract}

Index Terms - Lactide, polymerization, ROP, schiff base, transition metal.

\section{INTRODUCTION}

Poly(lactic acid) (PLA) [1], produced by the ring-opening polymerization (ROP) of lactide (LA), is a leading biodegradable and biocompatible polyester and their degradation into nontoxic components (water and carbon dioxide) make polylactides (PLAs) very useful for its biomedical and pharmaceutical applications such as controlled drug delivery systems. [2], [3] Owing to their mechanical properties, PLAs are widely used in surgery as sutures, orthopedic applications, tissue engineering and biodegradable internal fixation devices for repair of fractures to small bones and joints [4].

The preventive use in biomedical application is dependent on the extent to which the metal residues are removable upon quenching the polymerization. As removal of metal can never be zero, a preferred and feasible industrial process should employ metals in which the residues are not cytotoxic. It is practical to use environmentally benign metals that are part of the mammalian anatomy, so that there will be no harm for metal. [5] A number of different metal initiators and catalysts have been used in the ROP of lactides, including compounds of aluminum, lithium, magnesium, iron, tin, titanium, or zinc etc. Recently, catalysts based on transition metals have received increased attention because these elements can be metabolized in the body. [6] Comparatively, metal complexes with high electron transfer ability, moderate Lewis acidity and stability associated with reactive intermediates, should be the

Manuscript received July 15, 2016; revised October 10, 2016

S. Mantri is with the Ravenshaw University, India

H. C. Pradhan is with the National Institute of Technology, Raipur, India

T. Maharana is with the Department of Chemistry, National Institute of Technology, Raipur, India (e-mail: mtungabidya@gmail.com)

A. K. Sutar is with Catalysis Research Lab, Department of Chemistry, Ravenshaw University, Cuttack-3, Odisha, India (e-mail: dralekhasutar@gmail.com). topic of in depth investigations. Metal complexes should be biocompatible metal supporting the survival of life.

Currently almost all commercial PLAs are prepared using FDA-approved stannous octanoate as mediator. The activity of metal complexes of Schiff base ligands varies with the structure and nature of Schiff base ligands, hence an effort has been made to synthesize the metal complex of HMBBD (N,N'-bis (2-hydroxy-3-methoxybenzaldehyde) benzene-1, 2-diamine) and to evaluate their catalytic activity in ROP of lactide. Investigations on activity of metal complexes of HMBBD Schiff base in catalysis of ROP of lactide is hardly available in the literature; hence, synthesis and characterization of metal complexes of HMBBD Schiff base for their structures and catalytic activity is of academic and commercial interest.

\section{EXPERIMENTAL}

\section{A. Materials}

Syntheses were performed under a dry nitrogen atmosphere using a combination of a glove box and standard Schlenk techniques. All solvents were of analytical grade and were dried and distilled prior to use. Toluene and dichloromethane were dried and distilled from sodium benzophenone and $\mathrm{P}_{2} \mathrm{O}_{5}$ respectively. Anhydrous metal salts, and benzene-1, 2-diamine (BD) were purchased from HiMedia Laboratories Pvt. Ltd., Mumbai, India, 2-hydroxy-3-methoxybenzaldehyde (HMB) and benzyl alcohol were procured form E. Merck, India. $L$-Lactide (LA) was obtained from Sigma-Aldrich and used as received. Other chemicals were of analytical grade (>99.0 wt \%) and used as received.

\section{B. Synthesis of HMBBD Schiff Base and Complexation of Metal Ions}

HMBBD Schiff base was synthesized by the modified procedure reported in the literature. The reaction mixture containing 2-hydroxy-3-methoxybenzaldehyde (HMB) (20.00 mmol, $3.04 \mathrm{~g}$ ) and benzene-1,2-diamine (BD) (10.00 mmol, $1.08 \mathrm{~g}$ ) in methanol was refluxed at $60^{\circ} \mathrm{C}$ for about $2 \mathrm{~h}$. The reaction mixture on cooling to low temperature produced orange colored crystals, which were filtered and recrystallized with chloroform. The metal complexes of HMBBD Schiff base were prepared by taking $100 \mathrm{ml}$ methanolic solution mixture of Schiff base $20.00 \mathrm{mmol}(7.53 \mathrm{~g}$ ) and $20.00 \mathrm{mmol}$ of metal salt in a round bottom flask and refluxing the reaction mixture at $60^{\circ} \mathrm{C}$ for $5 \mathrm{~h}$. All reactions were performed under nitrogen atmosphere. Finally, metal complexes were recrystallized in methanol and dried in a vacuum desiccator. The loading of metal ion on HMBBD Schiff base was 
calculated as complexation of metal ion using the following equation.

Complexation of metal ion $=\frac{\text { Amount of metal loaded }}{\text { Amount of Schiff base used for loading }} \times 100$

\section{M-HMBBD Complex in Ring Opening Polymerization} of L-lactide

A typical polymerization procedure was exemplified by the synthesis of PLA-150 at room temperature. To a rapidly stirred solution of M-HMBBD $(0.133 \mathrm{mmol})$ in toluene (20 $\mathrm{mL})$, L-lactide $(0.72 \mathrm{~g}, 20 \mathrm{mmol})$ was added along with requisite amount of benzyl alcohol. A rise in viscosity was observed and finally the stirring was ceased after $24 \mathrm{~h}$. Volatile materials were removed under vacuum, and the residue was extracted with THF $(30 \mathrm{~mL})$. The extraction was dried again and the white precipitate was washed with n-hexane three times and dried under vacuum overnight, giving a crystalline white solid.

\section{RESULTS AND DISCUSSION}

The catalytic activity of metal complexes has been controlled significantly by varying the nature of Schiff base ligands and using metal ions in different oxidation states. The activity of catalysts also varied with the amount of Schiff base and metal ions. To analyze the effect of type of metal ions, the HMBBD Schiff base was loaded with cobalt(II), copper(II), nickel(II) and zinc(II) ions and the complexes were analyzed for their structure, stability and catalytic activity towards ROP of lactide.

\section{A. Synthesis and Characterization of HMBBD Schiff Base and Its Metal Complexes}

The HMBBD Schiff base was obtained by refluxing HMB and BD to produce a substantial yield (94.4 wt \%) (Scheme $1)$.

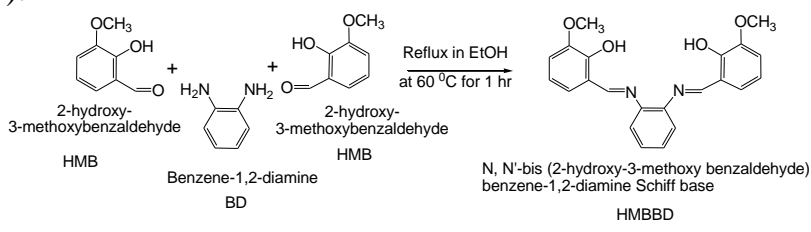

Scheme 1. Synthesis of N, N'-bis (2-hydroxy-3-methoxybenzaldehyde) benzene-1,2-diamine (HMBBD) Schiff base.

The IR spectrum of HMBBD Schiff base showed absorption bands at $1609 \mathrm{~cm}^{-1}(>\mathrm{C}=\mathrm{N}), 1260 \mathrm{~cm}^{-1}(>\mathrm{C}-\mathrm{O})$ phenolic (Table I) and a broad band between 3050 and 2850 $\mathrm{cm}^{-1}$ was also observed, which was assigned to phenolic $\mathrm{OH}$ group. The electronic spectra of HMBBD Schiff base (Table II) showed absorption bands at $260 \mathrm{~nm}$ and $330 \mathrm{~nm}$, which were assigned to $\pi \rightarrow \pi^{*}$ and $n \rightarrow \pi^{*}$ transitions.

The elemental analysis of HMBBD Schiff base showed (wt \%): $\mathrm{C}=70.35, \mathrm{~N}=7.02$ and $\mathrm{H}=5.70$; Caltd (\%): $\mathrm{C}=$ $70.20, \mathrm{~N}=7.44$ and $\mathrm{H}=5.36$ (Table III), which corresponded to $\mathrm{C}_{22} \mathrm{H}_{20} \mathrm{~N}_{2} \mathrm{O}_{4}$ empirical formula of HMBBD Schiff base [7]. The molecular weight of Schiff base was $377.68 \mathrm{~g} \mathrm{~mol}^{-1}$ (Caltd $376.41 \mathrm{~g} \mathrm{~mol}^{-1}$ ).

The loading of metal ions on HMBBD Schiff base was carried out by refluxing the Schiff base in solution of metal salt at $60^{\circ} \mathrm{C}$ for $7 \mathrm{~h}$ (Scheme 2). The metal complex, after separation and purification was analyzed for their structures and loading of metal ions (Table IV). The complexation of $\mathrm{Co}(\mathrm{II}), \mathrm{Ni}(\mathrm{II}), \mathrm{Cu}(\mathrm{II})$ and $\mathrm{Zn}(\mathrm{II})$ ions on HMBBD Schiff base were $81.27 \mathrm{wt} \%, 88.88 \mathrm{wt} \%, 86.27 \mathrm{wt} \%$ and $77.71 \mathrm{wt} \%$ respectively. The efficiency of complexation of HMBBD Schiff base (\%EC) has shown dependence on the type of metal ions.

TABLE I: FTIR FREQUENCIES OF HMBBD SCHIFF BASE AND ITS METAL COMPLEXES

\begin{tabular}{c|c|c|c|c|c}
\hline \multirow{2}{*}{ Compounds } & \multicolumn{5}{|c}{ Absorption frequencies $/ \mathrm{cm}^{-1}$} \\
\cline { 2 - 6 } & $v_{\mathrm{C}=\mathrm{N}}$ & $v_{\mathrm{C}-\mathrm{O}}$ & $v_{\mathrm{OH}}$ (phenolic) & $v_{\mathrm{N}-\mathrm{O}}$ & $v_{\mathrm{C}-\mathrm{N}}$ \\
\hline HMBBD & 1609 & 1260 & $3050-2850$ & & \\
\hline Co-HMBBD & 1581 & 1288 & - & 555 & 420 \\
\hline Ni-HMBBD & 1586 & 1279 & - & 525 & 422 \\
\hline Cu-HMBBD & 1627 & 1251 & - & 568 & 444 \\
\hline Zn-HMBBD & 1590 & 1280 & - & 561 & 418 \\
\hline
\end{tabular}

TABLE II: TRANSITION FREQUENCIES IN UV SPECTRA OF HMBBD SCHIFF BASE AND ITS METAL COMPLEXES

\begin{tabular}{c|c|c|c|c}
\hline \multicolumn{5}{c}{ BASE AND ITS METAL COMPLEXES } \\
\cline { 2 - 5 } Compounds & $\pi \rightarrow \pi *$ & $\mathrm{n} \rightarrow \pi *$ & $\mathrm{C} \rightarrow \mathrm{T}$ & $\mathrm{d} \rightarrow \mathrm{d}$ \\
\hline HMBBD & 260 & 330 & - & - \\
\hline Co-HMBBD & 229 & 299 & 359 & - \\
\hline Ni-HMBBD & 246 & 292 & 312 & 403 \\
\hline Cu-HMBBD & 250 & 326 & 347 & 444 \\
\hline Zn-HMBBD & 241 & 303 & - & - \\
\hline
\end{tabular}

TABLE III: ELEMENTAL ANALYSIS OF HMBBD SCHIFF BASE AND ITS METAL IONS COMPLEXES

\begin{tabular}{c|c|c|c}
\hline Compounds & Carbon/wt\% & Nitrogen/wt\% & Hydrogen/wt\% \\
\hline \multirow{2}{*}{ HMBBD } & 70.35 & 7.02 & 5.70 \\
& $(70.20)$ & $(7.44)$ & $(5.36)$ \\
\hline \multirow{2}{*}{ Co-HMBBD } & 61.23 & 6.32 & 4.56 \\
& $(60.98)$ & $(6.46)$ & $(4.19)$ \\
\hline \multirow{2}{*}{ Ni-HMBBD } & 60.51 & 6.19 & 4.13 \\
& $(61.01)$ & $(6.47)$ & $(4.19)$ \\
\hline \multirow{2}{*}{ Cu-HMBBD } & 61.75 & 6.24 & 4.21 \\
& $(60.34)$ & $(6.40)$ & $(4.14)$ \\
\hline \multirow{2}{*}{ Zn-HMBBD } & 59.87 & 6.14 & 4.28 \\
& $(60.08)$ & $(6.37)$ & $(4.13)$ \\
\hline \multicolumn{3}{|c}{ Data in parenthesis are theoretical. }
\end{tabular}

TABLE IV: EFFICIENCY OF COMPLEXATION (EC) OF METAL IONS (WT\%)

\begin{tabular}{c|c}
\hline Metal ions & HMBBD Schiff base \\
\hline $\mathrm{Co}($ II) ions & 81.27 \\
\hline $\mathrm{Ni}$ (II) ions & 88.88 \\
\hline $\mathrm{Cu}$ (II) ions & 86.27 \\
\hline $\mathrm{Zn}$ (II) ions & 77.71 \\
\hline
\end{tabular}

$[\mathrm{HMBBD}]=20 \mathrm{mmol},[$ Metal ions $]=20 \mathrm{mmol}$

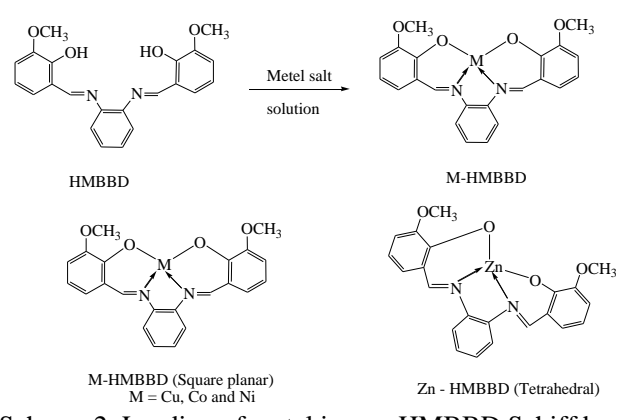

Scheme 2. Loading of metal ion on HMBBD Schiff base.

The IR spectrum of HMBBD Schiff base showed absorption bands at $1609 \mathrm{~cm}^{-1}(>\mathrm{C}=\mathrm{N}), 1260 \mathrm{~cm}^{-1}(>\mathrm{C}-\mathrm{O})$ phenolic and a broad band between 3050 and $2850 \mathrm{~cm}^{-1}$ was also observed, which was assigned to phenolic $\mathrm{OH}$. But the complexation of metal ion with HMBBD Schiff base showed significant variations in IR bands for $>\mathrm{C}=\mathrm{N}$ and $>\mathrm{C}-\mathrm{O}$ 
(phenolic) groups. Further, new absorption bands were also appeared due to the formation of $\mathrm{M}-\mathrm{O}$ and $\mathrm{M}-\mathrm{N}$ bonds in M-HMBBD complex (Table I), which were absent in FTIR spectrum of HMBBD Schiff base. The disappearance of phenolic absorption band between 2850 and $3050 \mathrm{~cm}^{-1}$ in the IR spectrum of HMBBD Schiff base after the complexation of metal ions was an evidence for the complexation of metal ions with HMBBD Schiff base [6].

The complexation of metal ions with Schiff base was further confirmed by comparing electronic spectra of metal complexes and pure HMBBD Schiff base. The electronic spectra of HMBBD Schiff base (Table II) showed absorption bands at $260 \mathrm{~nm}$ and $330 \mathrm{~nm}$, which were assigned to $\pi \rightarrow \pi^{*}$ and $n \rightarrow \pi^{*}$ transitions. But the M-HMBBD complex showed hypsochromic shift in $\pi \rightarrow \pi{ }^{*}$ transition (Table II). And the $n$ $\rightarrow \pi^{*}$ transition upon complexation with cobalt(II), copper(II), nickel(II) and zinc(II) ions has also shown a decrease in frequency of $\mathrm{n} \rightarrow \pi^{*}$ transition on complexation with HMBBD Schiff base (Table II). These variations in $\pi \rightarrow \pi^{*}$ and $\mathrm{n} \rightarrow \pi^{*}$ transitions were taken as concrete proof for the complexation of metal ions. In addition to these variations in transition frequencies, the shift in frequencies corresponding to charge transfer $(\mathrm{C} \rightarrow \mathrm{T})$ and $\mathrm{d} \rightarrow \mathrm{d}$ transitions were also used to differentiate the Schiff base and metal complexes.

The magnetic moment $(\mu)$ of HMBBD Schiff base metal complexes were determined and compared with their theoretical values and their structure have been determine. and to verify the molecular weight of metal complexes determined by vapor pressure osmometer. The elemental analysis of $\mathrm{Cu}-\mathrm{HMBBD}$ complex showed (wt \%): $\mathrm{C}=61.75$, $\mathrm{N}=6.24$ and $\mathrm{H}=4.21$; Caltd (\%): $\mathrm{C}=60.34, \mathrm{~N}=6.40$ and $\mathrm{H}$ $=4.14$, which corresponded to $\mathrm{C}_{22} \mathrm{H}_{18} \mathrm{CuN}_{2} \mathrm{O}_{4}$ empirical formula of $\mathrm{Cu}-\mathrm{HMBBD}$ complex (Table III). The elemental analysis of cobalt, nickel and zinc complexes correspond to their empirical formula.

The stochiometry of metal complexes of HMBBD have shown 1:1 ratio of metal ions and HMBBD Schiff base. The electronic spectra and magnetic moment $(\mu)$ of metal complexes have suggested that HMBBD Schiff base complexes of cobalt(II), copper(II) and nickel(II) ions were square planar $\left(\mathrm{dsp}^{2}\right)$ in geometry with $\mathrm{t}_{2 \mathrm{~g}}{ }^{6} \mathrm{e}_{\mathrm{g}}{ }^{1}, \mathrm{t}_{2 \mathrm{~g}}{ }^{6} \mathrm{e}_{\mathrm{g}}{ }^{2}$ and $\mathrm{t}_{2 \mathrm{~g}}{ }^{6} \mathrm{e}_{\mathrm{g}}{ }^{3}$ electronic configurations, whereas the HMBBD Schiff base complexes of zinc(II) ions was tetrahedral $\left(\mathrm{sp}^{3}\right)$ in geometry with $\mathrm{t}_{2 \mathrm{~g}}{ }^{6} \mathrm{e}_{\mathrm{g}}{ }^{4}$ electronic configuration.

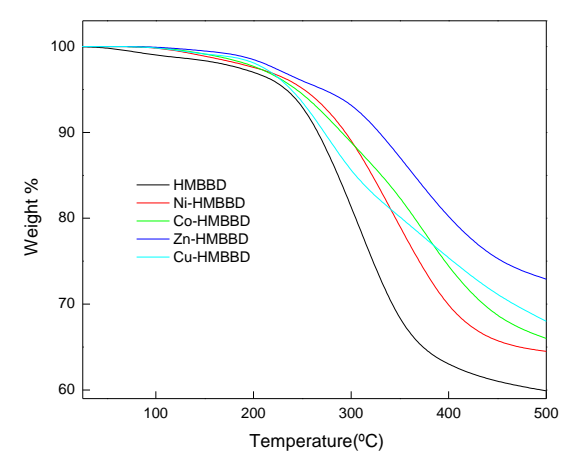

Fig. 1. TG curves of HMBBD Schiff base and its metal complexes.

The complexation of metal ions on HMBBD Schiff base (Table IV and Fig. 1) has increased thermal stability as determined by TG and DTG analysis of these metal complexes. The weight loss in metal complexes was studied up to $500^{\circ} \mathrm{C}$ at a heating rate of $5^{\circ} \mathrm{C} / \mathrm{min}$ in nitrogen atmosphere.

The TGA of HMBBD Schiff base showed a weight loss of $40.1 \mathrm{wt} \%$ at $500{ }^{\circ} \mathrm{C}$, but its cobalt(II), nickel(II), copper(II) and zinc(II) ions complexes has shown weight loss of 34.0, $35.5,32.0$ and $27.1 \mathrm{wt} \%$, respectively at same temperature, which was clear indication that zinc(II) ion complex was more stable in comparison to other metal ions and the stability order of HMBBD Schiff base complexes were found to be in order of, $\mathrm{Zn}$ (II) $>\mathrm{Cu}$ (II) $>\mathrm{Co}$ (II) $>\mathrm{Ni}$ (II) $>$ HMBBD Schiff base. The weight loss at $500^{\circ} \mathrm{C}$ was attributed to the decomposition of metal complexes of HMBBD Schiff base.

The high thermal stability of metal ions complexes of HMBBD Schiff base has indicated that supported metal complexes may be applied as catalysts in high temperature reactions.

\section{B. Evaluation of Catalytic Activities of $\mathrm{M}-\mathrm{Hmbbd}$ Complexes towards Ring Opening Polymerization of L-Lactide}

On the basis of the "immortal" property of lactide polymerization demonstrated by several metal complexes [1] and the evidence of in situ formation of metal alkoxide in the presence of alcohol, the complex M-HMBBD was expected to behave as catalysts towards the ROP of lactide in the presence of benzyl alcohol. The M-HMBBD in presence of benzyl alcohol does initiate the ring-opening polymerization of $L$-lactide (LA) in dichloromethane at $30^{\circ} \mathrm{C}$ (Scheme 3). All the runs displayed good activities for the polymerization of $L$-lactide and great control of molecular weight, and the presence of benzyl alcohol has a significant influence on the polymerization behavior of the M-HMBBD.
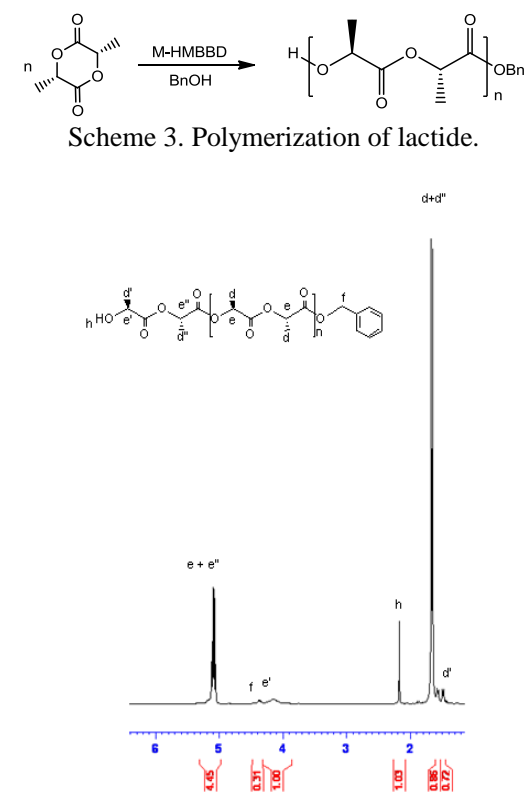

Fig. $2 .{ }^{1} \mathrm{H}$ NMR spectrum of PLLA-150 (150 indicates $\left.[\mathrm{LA}]_{0} /[\mathrm{BnOH}]=150\right)$ catalyzed by $\mathrm{Cu}-\mathrm{HMBBD}$.

Ring-opening polymerization of $L$-lactide using complex M-HMBBD, with a monomer to benzyl alcohol ratio 150/1 has been systematically studied at $30^{\circ} \mathrm{C}$ (Table V). It is worth noting that complex M-HMBBD is more active in $\mathrm{CH}_{\mathbf{2}} \mathrm{Cl}_{\mathbf{2}}$ than in toluene or in THF. The slowest polymerization rate is 
found in THF probably caused by the coordination ability of THF with metal to retard the reaction rate. Toluene is non polar solvent and $\mathrm{CH}_{2} \mathrm{Cl}_{2}$ is polar aprotic solvent. Thus, the polymerization is somewhat higher in $\mathrm{CH}_{2} \mathrm{Cl}_{2}$ than that in toluene.

From the polymerization results listed in Table VI, several structure-activity trends may be drawn. Experimental results indicate that compound M-HMBBD is an efficient catalyst for ROP of $L$-lactide in the presence of $\mathrm{BnOH}$, when $[\mathrm{LA}] /[\mathrm{BnOH}]$ ratio is ranging from 50 to 200 .

To understand the initiating processes, ${ }^{1} \mathrm{H}$ NMR studies on the PLLA, catalyzed by M-HMBBD with $\mathrm{BnOH}$ as an initiator are carried out. The ${ }^{1} \mathrm{H}$ NMR spectrum of PLLA-150 by $\mathrm{Cu}$-HMBBD complex (Fig. 2), prepared from a $[\mathrm{LA}]_{0} /[\mathrm{BnOH}]$ ratio of 150 , indicates that the polymer chain is capped with a benzyl ester group on one end and a hydroxyl group on the other end, suggesting that the initiation occurred through the insertion of the benzyl alkoxy group into $L$-lactide, giving a copper alkoxide intermediate, which further reacts with an excess of $L$-lactide yielding polyesters. The polymerization procedures agree with the process found with other metal alkoxides [9].

TABLE V: POLYMERIZATION OF L-LACTIDE USING M-HMBBD IN $\mathrm{CH}_{2} \mathrm{CL}_{2}$ AT $30^{\circ} \mathrm{C}$

\begin{tabular}{|c|c|c|c|c|c|}
\hline \multirow{2}{*}{ Entry } & \multirow{2}{*}{ Complexes } & \multirow{2}{*}{ Parameter } & \multicolumn{3}{|c|}{ Solvents } \\
\hline & & & $\mathrm{CH}_{2} \mathrm{Cl}_{2}$ & Toluene & THF \\
\hline \multirow{3}{*}{1} & \multirow{3}{*}{ Co-HMBBD } & Conversion $(\%)^{\mathrm{a}}$ & 79.3 & 69.3 & 50.8 \\
\hline & & $M_{n}(\text { Theory })^{\mathrm{b}}\left(\mathrm{g} \mathrm{mol}^{-1}\right)$ & 17200 & 15100 & 11100 \\
\hline & & $M_{n}(\mathrm{VPO})^{\mathrm{c}}\left(\mathrm{g} \mathrm{mol}^{-1}\right)$ & 19100 & 16400 & 13300 \\
\hline \multirow{2}{*}{2} & \multirow{2}{*}{ Ni-HMBBD } & Conversion $(\%)^{\mathrm{a}}$ & 86.1 & 80.0 & 61.3 \\
\hline & & $M_{n}(\mathrm{VPO})^{\mathrm{c}}\left(\mathrm{g} \mathrm{mol}^{-1}\right)$ & 21300 & 19200 & 16100 \\
\hline \multirow{3}{*}{3} & \multirow{3}{*}{$\mathrm{Cu}-\mathrm{HMBBD}$} & Conversion $(\%)^{\mathrm{a}}$ & 92.4 & 80.7 & 56.5 \\
\hline & & $M_{n}$ (Theory $^{\mathrm{b}}\left(\mathrm{g} \mathrm{mol}^{-1}\right)$ & 20100 & 17500 & 12300 \\
\hline & & $M_{n}(\mathrm{VPO})^{\mathrm{c}}\left(\mathrm{g} \mathrm{mol}^{-1}\right)$ & 22900 & 19400 & 17100 \\
\hline \multirow[b]{2}{*}{4} & \multirow[b]{2}{*}{ Zn-HMBBD } & Conversion $(\%)^{\mathrm{a}}$ & 69.4 & 53.4 & 40.7 \\
\hline & & 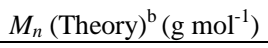 & 15100 & 11600 & 9000 \\
\hline
\end{tabular}

Conditions: $[L-\mathrm{LA}]_{0}=20 \mathrm{mmol}$, room temperature, Reaction time $24 \mathrm{~h},[\mathrm{M}]_{0} /[\mathrm{M}] /[\mathrm{BnOH}]=150 / 1 / 1, \mathrm{M}=\mathrm{Co} / \mathrm{Ni} / \mathrm{Cu} / \mathrm{Zn}$

${ }^{a}$ Percentage conversion of the monomer [(weight of polymer recovered/weight of monomer $) \times 100$ ]

${ }^{\mathrm{b}}$ Calculated by $\left[\left([\mathrm{LA}]_{0} /[\mathrm{BnOH}]\right) \times 144.13 \times\right.$ conversion $\left.\%+108.14\right]$

${ }^{\mathrm{c}}$ Determined by VPO.[8]

TABLE VI: POLYMERIZATION OF L-LACTIDE BY M-HMBBD IN PRESENCE OF BENZYL ALCOHOL WITH VARIATION IN LACTIDE EQUIVALENT

\begin{tabular}{|c|c|c|c|c|c|c|c|}
\hline Entry & Complexes & $\begin{array}{c}{[L-\mathrm{LA}]_{0} /} \\
{[\mathrm{Cu}] /[\mathrm{BnOH}]}\end{array}$ & Time (h) & Conversion $^{\mathrm{a}}(\%)$ & $\begin{array}{c}\left.M_{n} \text { (Theory }\right)^{\mathrm{b}} \\
\left(\mathrm{g} \mathrm{mol}^{-1}\right)\end{array}$ & $\begin{array}{c}M_{n}(\mathrm{VPO})^{\mathrm{c}} \\
\left(\mathrm{g} \mathrm{mol}^{-1}\right) \\
\end{array}$ & $\mathrm{PDI}^{\mathrm{e}}$ \\
\hline \multirow{3}{*}{1} & \multirow{3}{*}{ Co-HMBBD } & $50: 1: 1$ & 24 & 69.3 & 5100 & 6400 & 1.11 \\
\hline & & $150: 1: 1$ & 24 & 79.3 & 17200 & 19100 & 1.08 \\
\hline & & 200:1:1 & 24 & 82.4 & 23800 & 25300 & 1.10 \\
\hline \multirow{4}{*}{2} & \multirow{4}{*}{ Ni-HMBBD } & $50: 1: 1$ & 24 & 73.9 & 5400 & 7100 & 1.12 \\
\hline & & 100:1:1 & 24 & 82.4 & 11900 & 15400 & 1.11 \\
\hline & & 150:1:1 & 24 & 86.1 & 18700 & 21300 & 1.11 \\
\hline & & 200:1:1 & 24 & 89.3 & 25800 & 27100 & 1.13 \\
\hline \multirow{3}{*}{3} & \multirow{3}{*}{ Cu-HMBBD } & $50: 1: 1$ & 24 & 78.6 & 5800 & 7300 & 1.06 \\
\hline & & 100:1:1 & 24 & 88.9 & 12900 & 15100 & 1.06 \\
\hline & & 150:1:1 & 24 & 92.4 & 20100 & 22900 & 1.09 \\
\hline \multirow{4}{*}{4} & \multirow{4}{*}{ Zn-HMBBD } & $50: 1: 1$ & 24 & 60.1 & 4400 & 6200 & 1.07 \\
\hline & & 100:1:1 & 24 & 66.9 & 9700 & 12200 & 1.09 \\
\hline & & 150:1:1 & 24 & 69.4 & 15100 & 17000 & 1.07 \\
\hline & & $200: 1: 1$ & 24 & 73.8 & 21400 & 22900 & 1.10 \\
\hline
\end{tabular}

Conditions: $[L \text {-LA }]_{0}=20 \mathrm{mmol}$, room temperature. solvent $30 \mathrm{~mL}$ of $\mathrm{CH}_{2} \mathrm{Cl}_{2}$

${ }^{\mathrm{a}}$ Percentage conversion of the monomer [(weight of polymer recovered/weight of monomer) $\times 100$ ]

${ }^{\mathrm{b}}$ Calculated by $\left[\left([\mathrm{LA}]_{0} /[\mathrm{BnOH}]\right) \times 144.13 \times\right.$ conversion $\left.\%+108.14\right]$

${ }^{\mathrm{c}}$ Determined by VPO[8]

d Data not available

${ }^{\mathrm{e}}$ Obtained from GPC analysis and calibrated by polystyrene standard.

\section{Kinetics of Polymerization}

Kinetic studies for the polymerization of $L$-lactide have been performed by using M-HMBBD as catalysts in the presence of an initiator $\mathrm{BnOH}$ in the ratio $[\mathrm{LA}] /[\mathrm{M}] /[\mathrm{BnOH}]$ $=100 / 1 / 1$ (Fig. 3).

This plot implies that the polymerization reaction obeys first order kinetics. The $\ln [\mathrm{M}]_{\mathrm{o}} /[\mathrm{M}]_{\mathrm{t}}$ vs time plots is linear. [10] The values of the apparent rate constant $\left(\mathrm{k}_{\mathrm{app}}\right)$ may be 
calculated from the slope of these plots. The value of $\mathrm{k}_{\mathrm{app}}$ for $L$-lactide polymerization in the presence of initiator was found to be $0.04649 \mathrm{~h}^{-1}$ (Fig. 3), $0.06317 \mathrm{~h}^{-1}, 0.0918 \mathrm{~h}^{-1}$ and $0.02935 \mathrm{~h}^{-1}$ for Co-HMBBD, Ni-HMBBD, Cu-HMBBD and Zn-HMBBD complexes respectively.

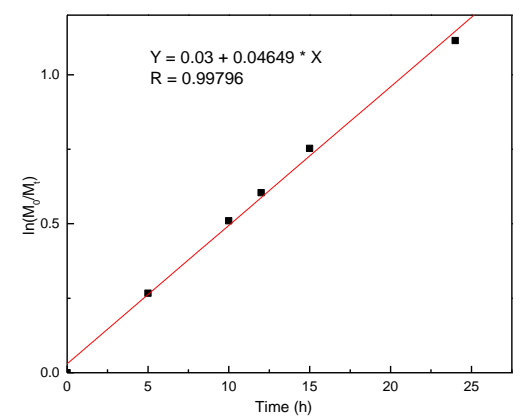

Fig. 3. Semilogarithmic plots of $L$-lactide conversion in time catalyzed by Co-HMBBD in the presence of BnOH: $[L-\mathrm{LA}]_{0} /[\mathrm{Co}] /[\mathrm{BnOH}]=100 / 1 / 1$.

\section{CONCLUSION}

To evaluate the role of HMBBD Schiff base complexes of metal ions in the ring opening polymerization of $L$-lactide in the presence of benzyl alcohol, the copper(II), nickel(II), cobalt(II) and zinc(II) ion complexes of HMBBD Schiff base have been synthesized successfully and their activities were compared at different concentrations of lactide and different amount of benzyl alcohol. The selected metal ion complexes of HMBBD Schiff base were characterized using different techniques to obtain their structural information. The metal ion complexes of HMBBD Schiff base have shown high stability in leaching of metal ions. All the PLA produced by ROP of $L$-lactide shows higher molecular weight with above $80 \%$ conversion rate.

\section{ACKNOWLEDGMENT}

The authors are thankful to DST \& CSIR, New Delhi, India for funding. The authors are also grateful to Ravenshaw University and National Institute of Technology, Raipur for providing research facilities.

\section{REFERENCES}

[1] A. K. Sutar, T. Maharana, S. Dutta, C.-T. Chen, C.-C. Lin, "Ring-opening polymerization by lithium catalysts: An overview," Chem. Soc. Rev., vol. 39, pp. 1724-1746, 2010.

[2] T. Maharana, B. Mohanty, and Y. S. Negi, "Melt-solid polycondensation of lactic acid and its biodegradability," Prog. Polym. Sci, vol. 24, pp. 99-124, 2009

[3] K. E. Uhrich, S. M. Cannizzaro, R. S. Langer, and K. M. Shakesheff, "Polymeric systems for controlled drug release," Chem. Rev, vol. 99, pp. 3181-3198, 1999.

[4] R. Langer, "New methods of drug delivery," Science, vol. 249, pp. 1527-1533, 1990.

[5] G. B. Kharas, F. Sanchez-Riora, and D. K. Soverson, "Polymers of lactic acid," in Plastics from Microbes, D. P. Mobley Ed., Hanser Publishers, Munchen, Germany, 2004.

[6] L. Piao, M. Deng, X. Chen, L. Jiang, and X. Jing, "Ring-opening polymerization of $\varepsilon$-caprolactone and 1-lactide using organic amino calcium catalyst," Polymer, vol. 44, pp. 2331-2336, 2003.
[7] A. K. Sutar, Y. Das, S. Pattnaik, A. Routaray, N. Nath, P. Rath, and T. Maharana, "Novel polystyrene-anchored zinc complex: Efficient catalyst for phenol oxidation," Chinese. J. Catal, vol. 35, pp. 1701-1708, 2014

[8] H. Alamri, J. Zhao, D. Pahovnik, and N. Hadjichristidis, "Phosphazene-catalyzed ring-opening polymerization of $\varepsilon$-caprolactone: influence of solvents and initiators," Polym. Chem, vol. 5, pp. 5471-5478, 2014.

[9] D. Appavoo, B. Omondi, I. A. Guzei, J. L. V. Wyk, O. Zinyemba, and J. Darkw, "Bis(3,5-dimethylpyrazole) copper(ii) and zinc(ii) complexes as efficient initiators for the ring opening polymerization of E-caprolactone and d,1-lactide," Polyhedron, vol. 69, pp. 55-60, 2014.

[10] A. Routaray, S. Mantri, N. Nath, A. K. Sutar, "Maharan T. Nickel(II) complex catalyzed ring-opening polymerization of lactide," Polyhedron, vol. 119, pp. 335-341, 2016.

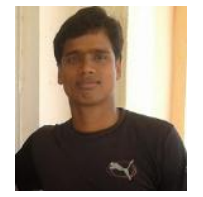

Somanath Mantri was born in Odisha, India, and obtained his B.Sc. in chemistry from Utkal University, M.Sc. and M.Phil in chemistry from North Odisha University. In 2015, he moved to Ravenshaw University to carry out her Ph.D. on polymer chemistry under the supervision of Dr. Alekha Kumar Sutar. His research interests include the development of novel biocompatible and bioassimilable metal complexes for ROP of cyclic esters, and biodegradable polymers.

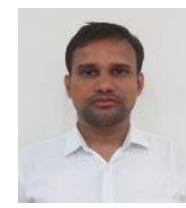

Harish Chandra Pradhan was born in Odisha, India, and obtained his B.Sc. in chemistry, M.Sc. in advanced inorganic chemistry and M.Phil in chemistry from Sambalpur University. Presently, he is pursuing his Ph.D. degree in chemistry at NIT Raipur under the supervision of Dr. Tungabidya Maharana in the area of polymer chemistry and Catalysis. His research interests include heterogeneous catalysts, the development of novel metal complexes for carbon dioxide sequestration, and biodegradable polymers.

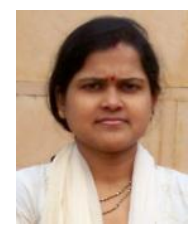

Tungabidya Maharana completed her Ph.D. degree at Indian Institute of Technology, Roorkee, under the supervision of Professor Y. S. Negi and Professor B. Mohanty, on polymer chemistry. She was a lecturer at Ravenshaw University, India (2011-2013). She is continuing as an assistant professor at National Institute of Technology, Raipur, India since 2013. Her research interests include ring opening polymerization (ROP) of cyclic esters, copolymerization of carbon dioxide, biodegradable polymers by graft-copolymerization, polycondensation and ROP.

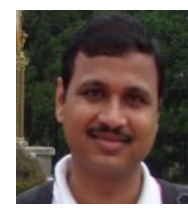

Alekha Kumar Sutar obtained his Ph.D. degree from Indian Institute of Technology, Roorkee on polymer supported catalysis. Then after he joined as Postdoctoral Fellow in the group of Prof. Chu-Chieh Lin at National Chung Hsing University, Taiwan. Currently he is working as Assistant Professor at Ravenshaw University, India. His main research interests include development of biocompatible and bioassimilable metal catalysts for the ring opening polymerization (ROP) of cyclic esters and copolymerization of carbon dioxide, polymer supported catalysis and biodegradable polymers. 